\title{
Clemson University
}

\section{TigerPrints}

Publications

Mechanical Engineering

$5-2016$

\section{D Carbon-Electrode Dielectrophoresis for Enrichment of a Small Cell Population from a Large Sample Volume}

Monsur Islam

Clemson University

Rucha Natu

Clemson University

Maria Fernanda Larraga-Martinez

Clemson University

Guillermo Contreras-Dávila

Clemson University

Rodrigo Martinez-Duarte

Clemson University, rodrigm@clemson.edu

Follow this and additional works at: https://tigerprints.clemson.edu/mecheng_pubs

Part of the Mechanical Engineering Commons

\section{Recommended Citation}

Please use the publisher's recommended citation. http://ecst.ecsdl.org/content/72/1/97.abstract

This Article is brought to you for free and open access by the Mechanical Engineering at TigerPrints. It has been accepted for inclusion in Publications by an authorized administrator of TigerPrints. For more information, please contact kokeefe@clemson.edu. 


\title{
3D Carbon-Electrode Dielectrophoresis for Enrichment of a Small Cell Population from A Large Sample Volume
}

\author{
M. Islama , R. Natu ${ }^{\mathrm{a}}$, M. F. Larraga-Martinez ${ }^{\mathrm{a}, \mathrm{b}}$, G. Contreras-Dávila ${ }^{\mathrm{a}, \mathrm{c}}$, and R. Martinez- \\ Duarte $^{\mathrm{a}}$ \\ ${ }^{a}$ Department of Mechanical Engineering, Clemson University, Clemson, South Carolina \\ 29631, USA \\ b Department of Biomedical Engineering, University of Iowa, Iowa City, Iowa 52242, \\ USA \\ c Department of Electrical and Computer Engineering, Tecnologico de Monterrey, \\ Monterrey, Mexico
}

Isolation and enrichment of cells from a diluted sample is necessary for different clinical applications. Here we have demonstrated the use of 3D carbon electrode dielectrophoresis (DEP) to process a diluted yeast sample featuring concentration as low as $10^{2}$ cells $/ \mathrm{ml}$. The yeast cells in the sample were first trapped on carbon electrodes by implementing positive DEP force and then released concentrated in a small volume of clean buffer. The maximum limit of the cell trapping for our device was found to be around 4000 cells. Using $10 \mu \mathrm{l} / \mathrm{min}$, an enrichment of $154.2 \pm 23.7$ folds was achieved, where sample of $10^{2}$ cells/ml concentration was enriched up to $4 \times 10^{4}$ cells/ml. Upon increasing the flow rate up to $30 \mu \mathrm{l} / \mathrm{min}$, the enrichment dropped down to $18.4 \pm 4$ folds due to the increase of drag force, though the enriched concentration around $10^{4}$ cells $/ \mathrm{ml}$ was still achieved.

\section{Introduction}

Cell enrichment and purification from a diluted sample volume are important steps in a number of clinical and environmental assay. One of the immediate applications is the identification of the blood pathogens which are generally present in the whole blood at a concentration of $1-100$ cells $/ \mathrm{ml}$ in the earlier stage of infection. In a typical clinical setting, around $30 \mathrm{ml}$ of blood is taken out from the patient's body and inoculated in a suitable culture media to allow the pathogenic cells to replicate to reach at least a concentration of $10^{3}$ copies/ml which is necessary for detection with commercially available biosensors. The culturing method requires days to weeks to reach up to the specific concentration to facilitate detection. But in some cases, at this point the patient is already compromised. Hence timely isolation and enrichment of few pathogenic cells from a diluted sample can make it possible to complete the whole process from blood collection to detection in few hours. Consequently the administration of proper antibody can be started to eradicate the replication of the pathogenic cells and prevent sepsis.

The present state-of-art for cell isolation and enrichment include Fluorescence Activated Cell Sorting (FACS) and Magnetic Activated Cell Sorting (MACS) which are highly sensitive and capable of sorting 50,000 cells/min. The disadvantages of these marker specific cell sorting methods are high cost and complex set up which requires 
specialized personals to perform the cell sorting. Also the flow rate used in these methods is low and these methods require at least 20 hours to sort and enrich low abundance cells from a large sample volume [1,2]. Several other label-free techniques including micropillar sieving [3], free-flow electrophoresis (FFE) [4] and dielectrophoresis (DEP) [5] have been also employed for the enrichment of biological cells from diluted samples. Recently DEP has been becoming popular in research community as a powerful label free technique for manipulation, isolation and purification of bioparticles including bacteria, DNA and infected cells from whole blood [6-8]. The DEP force depends only on the dielectric properties of the targeted cells, hence it does not need any pre-labelling step. The fabrication of DEP device is also inexpensive in comparison to FACS and MACS. Use of 3D electrodes makes it possible to achieve high separation throughput of the device.

In this work we use 3D carbon electrode dielectrophoresis to process a large volume of yeast sample which features low concentration of yeast cells $\left(10^{2}-10^{3}\right.$ cells $\left./ \mathrm{ml}\right)$. We isolate the yeast cells from the sample and concentrate the isolated cells in a small volume of clean buffer to enrich the cell concentration. We determine the maximum cell trapping capacity of our DEP device and present the enrichment capability of the device for different cell concentration of initial sample. We further explore the effect of different flow rates on the enrichment for the concentration of $10^{2}$ cells $/ \mathrm{ml}$.

\section{Theory}

DEP can be defined as the translational movement of a dielectric particle in a media upon interaction with a non-uniform electric field [9]. The DEP force $\left(F_{D E P}\right)$ on a spherical particle of radius $r$ can be expressed as:

$$
F_{D E P}=2 \pi r^{3} \varepsilon_{m} \operatorname{Re}\left[f_{C M}\right] \nabla E_{R M S}^{2}
$$

where, $\varepsilon_{m}$ represents the permittivity of the media, $\operatorname{Re}\left[f_{C M}\right]$ is the real part of the Clausius-Mossotti factor and $\nabla E_{R M S}$ is the magnitude of the gradient of the applied electric field. The $\operatorname{Re}\left[f_{C M}\right]$ is given by:

$$
\begin{aligned}
\operatorname{Re}\left[f_{C M}\right] & =\frac{\varepsilon_{p}^{*}-\varepsilon_{m}^{*}}{\varepsilon_{p}^{*}+2 \varepsilon_{m}^{*}} \\
\varepsilon^{*} & =\frac{j \sigma}{2 \pi f}
\end{aligned}
$$

where $\varepsilon_{p}^{*}$ denotes the complex permittivity of the particle and $\varepsilon_{m}^{*}$ represents the complex permittivity of the media. The complex permittivity term depends on the conductivity $(\sigma)$ of the particle or the media and the frequency $(f)$ of the applied electric field as shown in equation 3 . The imaginary number $\sqrt{-1}$ is represented by $j$. Positive value of the real part of the Clausius-Mossotti factor $\left(\operatorname{Re}\left[f_{C M}\right]\right)$ indicates the DEP force which causes the migration of the targeted particle towards the higher electric field and this phenomenon is termed as positive DEP (pDEP). Negative sign of $\operatorname{Re}\left[f_{C M}\right]$ represents the opposite incidence where the particle move towards the lower or zero electric field and this 
incidence is defined as negative DEP (nDEP). For a flow through experiment, the positive DEP force must be higher than the hydrodynamic drag force to implement particle trapping on the electrodes.

\section{Materials and Methods}

\section{Fabrication of the Device:}

The device used in this work contains 3D carbon electrodes featuring $100 \mu \mathrm{m}$ height and $50 \mu \mathrm{m}$ diameter. These 3D carbon electrodes were fabricated by two step photolithography of SU-8 (Gersteltec Sarl, Switzerland), a negative photoresist, on a silicon substrate followed by a heat treatment at $1000{ }^{\circ} \mathrm{C}$ in constant nitrogen flow. The details of the fabrication is reported elsewhere [6-7,10-12]. The carbon electrodes were then integrated with a microfluidic channel, fabricated in a double sided pressure sensitive adhesive (PSA), and a pre-drilled polycarbonate cover [13]. The assembly was then roll-pressed with a laminator to seal the device. The fabrication process is illustrated in the Figure 1.

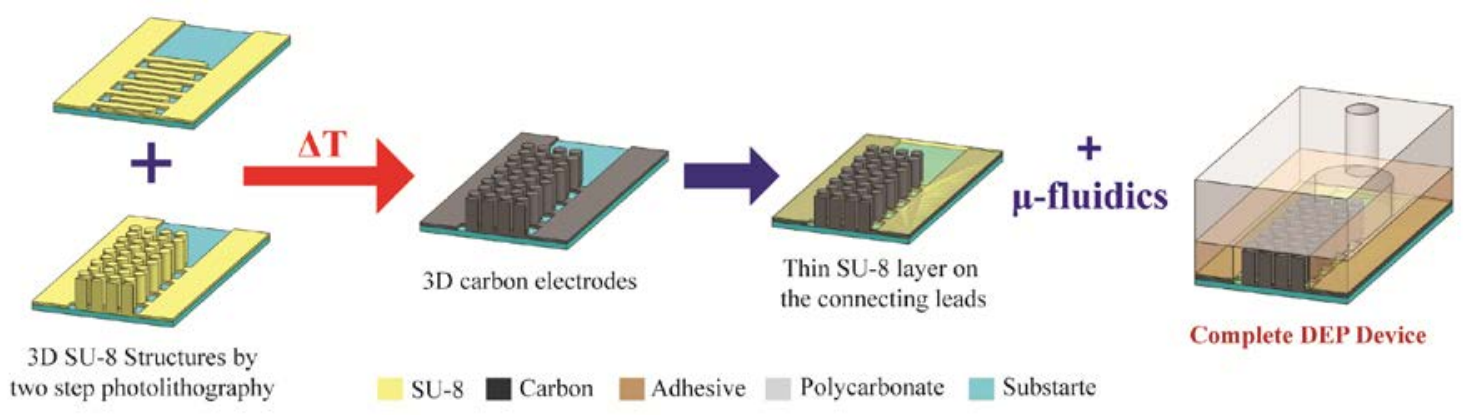

Figure 1. Schematic of the fabrication process of the carbon electrode DEP device

\section{Sample Preparation:}

A cell culture of Saccharomyces cerevisiae (Yeast, Sigma Aldrich, USA) in 0.1 M phosphate buffer saline (PBS) was grown overnight to a concentration of $10^{7} \mathrm{cells} / \mathrm{ml}$. An aqueous buffer solution containing $0.1 \%$ bovine serum albumin (BSA), $8.6 \mathrm{wt} \%$ sucrose and $0.3 \mathrm{wt} \%$ of dextrose was used here as the experimental media for DEP. The experimental sample was obtained by pelleting the cells using centrifugation at $5000 \mathrm{rpm}$ for 5 minutes followed by washing and re-suspending them in the buffer solution. Dilution with the buffer solution was used to achieve the cell concentration of $10^{2}-10^{6}$ cells/ml.

\section{Experimental Procedure:}

The DEP device was placed in an in-house made platform to integrate the fluidic and electric connection with the DEP device. A sinusoidal AC signal with 20 Vpp magnitude and $100 \mathrm{kHz}$ frequency was used to stimulate the carbon electrodes to implement positive DEP force. A sample volume of $500 \mu \mathrm{l}$ was flowed through the DEP chip when we processed the sample having concentration of $10^{3}-10^{6}$ cells $/ \mathrm{ml}$. We chose to flow $4 \mathrm{ml}$ for the sample with concentration $10^{2}$ cells $/ \mathrm{ml}$, as at least 200 cells were necessary for direct 
cell counting on the hemocytometer (Hausser Scientific, USA) used here. After processing the sample, $100 \mathrm{\mu l}$ of the clean buffer was flowed through the channel to wash the trapped cells as the electrodes were still polarized. After the wash, the polarizing signal was turned off. The trapped cells were carried away with the buffer and retrieved at the end of the device. A constant flow rate was maintained throughout the whole experiment. Fractions of $20 \mu \mathrm{l}$ were collected at the end of the device at different times of the experiment and analyzed for cell concentration. Three experiments were performed for each of the cell concentration.

\section{Results and Discussion}

The results for the experiments with different cell concentrations are presented in Figure 2a. Cell concentrations for 9 fractions were plotted. The control fraction represents the initial sample cell concentration. During the fractions labelled as Washes 1-4, the carbon electrodes were polarized for particle trapping. Hence negligible cell concentration was expected in these fractions. Fractions labelled as Elutes 1-4 were collected just after the electric field was turned off for cell release from the electrodes. Investigation of these fractions shows some interesting facts. Around 4000 cells were retrieved in the $80 \mu \mathrm{l}$ of the elute fractions for the experiments with sample having concentration of $10^{5}$ and $10^{6}$ cells $/ \mathrm{ml}$, whereas around 45000 and 310000 cells were processed respectively. Upon retrieval of these cells in small volume fractions, highest cell concentration in the order of $10^{5}$ cells/ml was obtained in the fraction Elute 1. Hence the saturation limit on cell trapping and concentration of retrieved cells for this specific experimental set up can be considered as 4000 cells and $10^{5}$ cells/ml respectively. Almost $100 \%$ retrieval of the incoming cells were achieved when we processed the sample having concentration $10^{4}-10^{2}$ cells $/ \mathrm{ml}$. For these samples, an enriched fraction can be observed at Elute 1. A cell enrichment up to $10^{5}$ cells/ml was achieved when we processed the sample with $10^{4}$ cells $/ \mathrm{ml}$ concentration. For the experiments with $10^{3}$ and $10^{2}$ cells $/ \mathrm{ml}$ concentration, the cell concentration at the fraction Elute 1 was obtained around $4 \times 10^{4}$ cells $/ \mathrm{ml}$. The enrichment in this work is quantified according to the Equation 4.

$$
\text { Enrichment }=\frac{\text { Cell Conc. at Elute } 1-\text { Contol Cell Conc. }}{\text { Control Cell Conc. }}
$$

The experiment with concentration $10^{6}$ cells/ml resulted in negative enrichment which could not be plotted in the logarithmic scale of enrichment vs control cell concentration graph as shown in Figure 2b. Cell enrichment obtained for the experiment with $10^{5}$ cell concentration is negligible. A cell enrichment of $11.2 \pm 3.3$ folds was achieved when we processed the sample with $10^{4}$ cells/ml concentration. Around $1800 \pm$ 481 cells which were originally suspended in $500 \mu \mathrm{l}$ of the sample were retrieved and concentrated in $20 \mu \mathrm{l}$ clean buffer. The experiments with $103 \mathrm{cells} / \mathrm{ml}$ resulted in enrichment of $19.4 \pm 2.5$ folds, as around $684 \pm 85$ cells out of $850 \pm 316$ cells originally present in $500 \mu \mathrm{l}$ sample were concentrated in the fraction Elute 1. For the sample with $10^{2}$ cells $/ \mathrm{ml}$ cell concentration, we were able to achieve an enrichment of $154.2 \pm 23.7$ folds. It should be noted that, our device was capable of concentrating around $816 \pm 125$ cells out of $1052 \pm 380$ cells originally present in $4 \mathrm{ml}$ of media in just $20 \mu 1$ of clean buffer. 


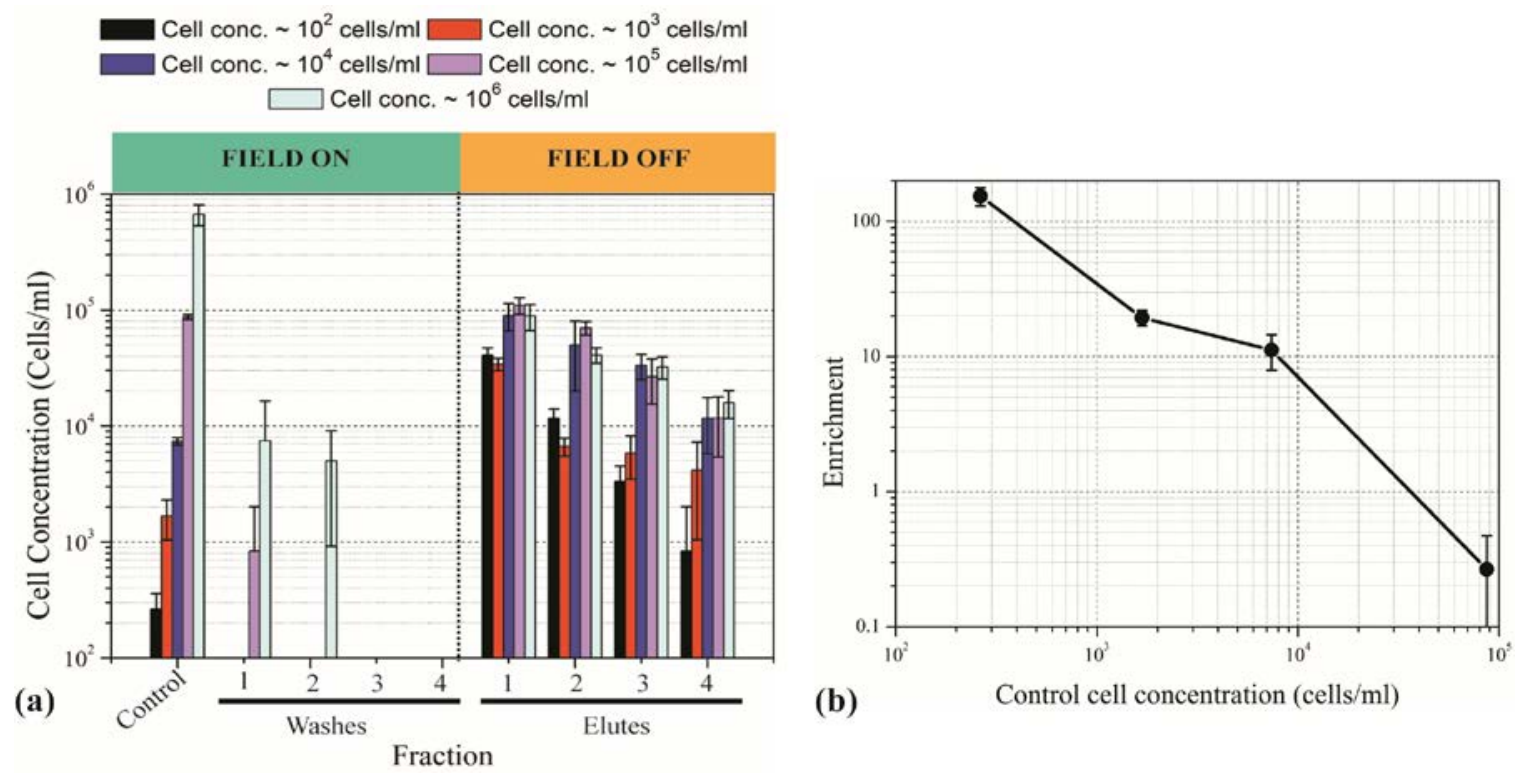

Figure 2: (a) Results of carbon electrode DEP of the yeast cells with different cell concentration at $20 \mathrm{~V}_{\mathrm{pp}}, 100 \mathrm{kHz}$ and $10 \mu \mathrm{l} / \mathrm{min}$; (b) Enrichment for different cell concentration

The total processing time for the sample having $10^{2}$ cells $/ \mathrm{ml}$ concentration was around 7 hours. In order to minimize the processing time, we repeated the experiments for 102 cells/ml concentration with the flow rates of $20 \mu \mathrm{l} / \mathrm{min}$ and $30 \mu \mathrm{l} / \mathrm{min}$ and investigated the effect of flow rates on the cell enrichment. The results for different flow rates were presented in Figure 3a. The increase in the flow rate enhances the drag force on the cells and results in less DEP trapping. Hence, less cell concentration in Elute 1 was achieved with the increasing flow rate. But it should be noted that the cell concentration at Elute 1 was enriched up to $10^{4}$ cells $/ \mathrm{ml}$ even with the flow rate of $30 \mu \mathrm{l} / \mathrm{min}$. Though the processing time was shortened significantly with the increasing flow rate, the enrichment also dropped drastically as shown in Figure 3b. The enrichment dropped down to $77.2 \pm 16$ folds as the flow rate increased to $20 \mu \mathrm{l} / \mathrm{min}$. But the total assay time also decreased to 3 hours 30 minutes. As the flow rate further increased to $30 \mu \mathrm{l} / \mathrm{min}$, the enrichment dropped to $18.4 \pm 4$ folds and the entire experiment could be completed in 2 hours 30 minutes.

\section{Conclusion}

In this work, isolation and enrichment of a small population of yeast cells has been successfully demonstrated using 3D carbon electrode dielectrophoresis by processing a large sample volume. Using the cell concentration of $10^{2}$ cells $/ \mathrm{ml}$, an enrichment up to 154.2 folds could be achieved by implementing the flow rate of $10 \mu \mathrm{l} / \mathrm{min}$. The enrichment value decreases rapidly with the increase in the flow rate. An enriched fraction up to $10^{4}$ cells $/ \mathrm{ml}$ concentration can be still achieved using the flow rate of 30 $\mu \mathrm{l} / \mathrm{min}$ in just 2 hour 30 mins. Enrichment of yeast cells be a useful prototype for isolation and enrichment of pathogenic yeast cells such as C. albicans, C. glabrata, C. parapsilosis, $C$. tropicalis and $C$. krusei which are responsible for invasive candidemia. Candidemia has been emerged to be a serious issue for hospitalized patients and responsible for $25-60 \%$ of the overall mortality [14]. The frequency of these Candida species of yeast cells in a sample is 10-100 cells/ml [15]. By using the enrichment 
method by 3D carbon electrode DEP, we would expect to achieve an enriched fraction volume of Candida cells up to $10^{4}$ cells/ml concentration in few hours, which can be used for identification either by biosensors or polymerase chain reaction.
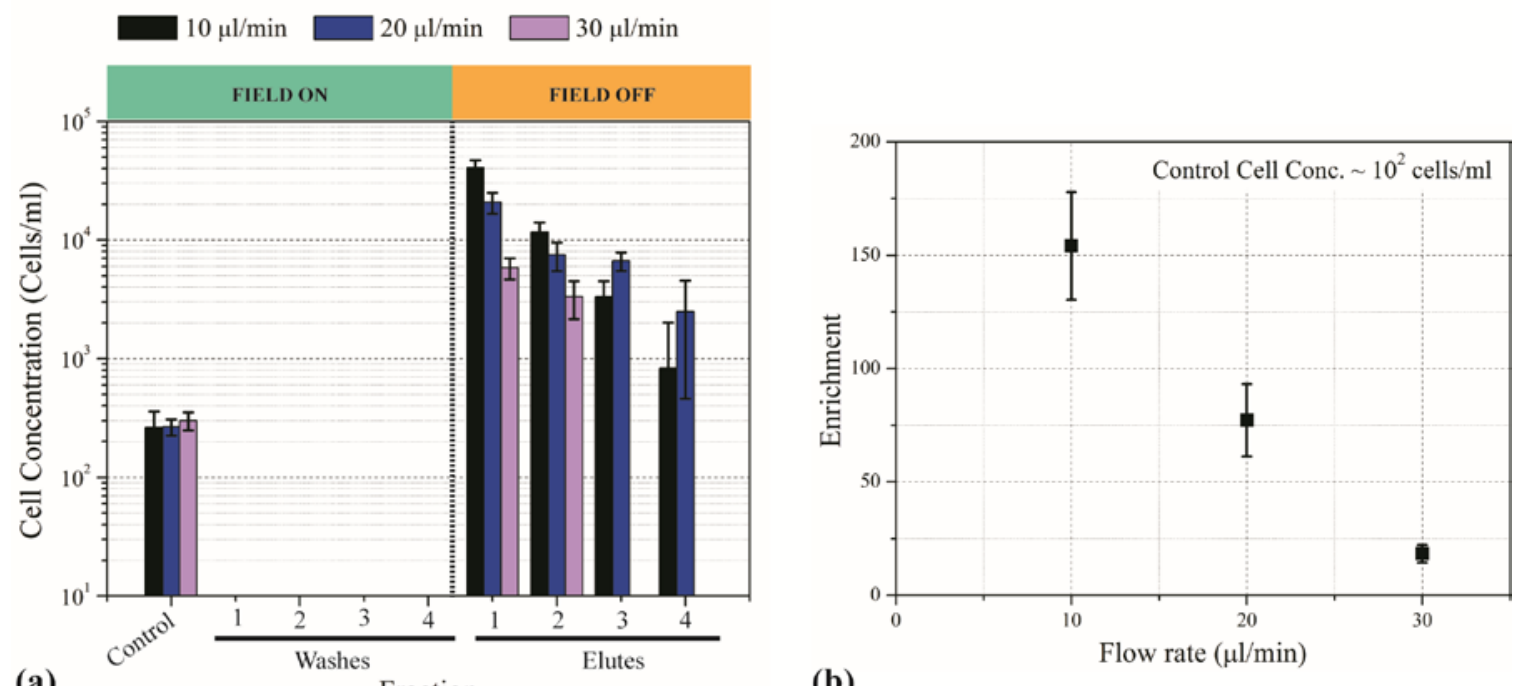

(b)

Figure 3. (a) Results of carbon electrode DEP of yeast cell of $10^{2}$ cells/ml concentration with different flow rates; (b) Enrichment for different flow rate.

\section{Acknowledgments}

The authors would like to thank Bill Delaney of Micro-Photonics Fabrication Facility of AMRL, Clemson University for his help in the fabrication of the DEP device.

\section{References}

1. J. Vykoukal, D. M. Vykoukal, S. Freyberg, E. U. Alt, and P. R. C. Gascoyne, Lab Chip, 8, 1386-1393 (2008).

2. U. Dharmasiri, M. a Witek, A. a Adams, and S. a Soper, Annu. Rev. Anal. Chem., 3, 409-31 (2010).

3. K. Y. Hwang et al., Anal. Chem., 80, 7786-7791 (2008).

4. S. Podszun et al., Lab Chip, 12, 451-7 (2012).

5. J. Marchalot et al., Biomicrofluidics, 9, 1-14 (2015).

6. R. Martinez-Duarte, F. Camacho-Alanis, P. Renaud, and A. Ros, Electrophoresis, 34, 1113-22 (2013).

7. M. D. C. Jaramillo, E. Torrents, R. Martínez-Duarte, M. J. Madou, and A. Juárez, Electrophoresis, 31, 2921-8 (2010).

8. P. Gascoyne et al., Lab Chip, 2, 70-5 (2002).

9. H. a. Pohl, J. Appl. Phys., 22, 869-871 (1951).

10. R. Martinez-Duarte, thesis, University of California, Irvine (2010). 
11. R. Martinez-Duarte, P. Renaud, and M. J. Madou, Electrophoresis, 32, 238592 (2011).

12. G. Mernier, R. Martinez-Duarte, R. Lehal, F. Radtke, and P. Renaud, Micromachines, 3, 574-581 (2012).

13. M. Islam, R. Natu, and R. Martinez-Duarte, Microfluid. Nanofluidics, 19, 973-985 (2015).

14. O. Gudlaugsson et al., Clin. Infect. Dis., 37, 1172-1177 (2003).

15. A. Telenti, J. M. Steckelberg, L. Stockman, R. S. Edson, and G. D. Roberts, Mayo Clin. Proc., 66, 1120-1123 (1991). 